\title{
A ABORDAGEM TEÓRICA DE A. I. MIKHAILOV SOBRE O TERMO INFORMAÇÃO CIENTÍFICA ${ }^{1}$
}

Roberto Lopes dos Santos Junior

Lena Vania Ribeiro Pinheiro

\section{Resumo:}

Estudo sobre a abordagem do pesquisador soviético A. I. Mikhailov (1905-1988), em sua produção bibliográfica, sobre aspectos referentes ao conceito informação científica, principal objeto de pesquisa do campo em Ciência da Informação na antiga União Soviética, e a analises feitas pelo autor sobre a definição, características e valores relacionados a esse termo. O estudo desses conceitos, quando possível, será relacionado à emergência e ao desenvolvimento da Ciência da Informação no período onde essas idéias foram desenvolvidas e publicadas (décadas de 1950 a 1970), onde essa nomenclatura exerceu considerável influencia para esse, na época, embrionário campo de pesquisa.

Palavras-chave:

Informação científica; A. I. Mikhailov; Epistemologia; História da Ciência da Informação

\section{THE THEORICAL APPROACH OF A. I. MIKHAILOV ABOUT THE TERM SCIENTIFIC INFORMATION}

\begin{abstract}
:
Study on the approach of the Soviet researcher A. I. Mikhailov (1905-1988), in his bibliographic production, about the concept "scientific information", the main object of research in Information Science field in the former Soviet Union, and also, analysis made by the author on the definition, characteristics and values related to this term. The study of these concepts, when possible, will be related to the emergence and development of Information Science in the period in which these ideas were developed and published (from 1950 to 1970), where this designation exercised considerable influence to, at the time, embryonic field of research.
\end{abstract}

\section{Keywords:}

Scientific information; A. I. Mikhailov; Epistemology; Information Science History

\footnotetext{
${ }^{1}$ Artigo proveniente de parte da dissertação A contribuição teórica de Alexander Ivanovich Mikhailov para a construção da Ciência da Informação. Rio de Janeiro, 2009. Do programa em pós-graduação em Ciência da Informação do Instituto Brasileiro de Informação em Ciência e Tecnologia (IBICT), convênio com a Universidade Federal Fluminense, 2009.
} 


\section{Introdução}

Entre diferentes pesquisadores relacionados ao campo de estudo da Ciência da Informação na antiga União Soviética, o mais influente, ou pelo menos o mais citado entre os autores brasileiros da área, foi Alexander Ivanovich Mikhailov (1905-1988). Mikhailov foi, por mais de trinta anos (1956-1988), diretor e coordenador do principal orgão de pesquisa em Ciência da Informação na URSS, o Instituto Estatal de Informação Cientifico e Técnica, ou VINITI e por duas vezes vice-diretor da Federação Internacional de Documentação, ou FID (entre 1969-1976 e 1981-1988), onde foi também coordenador de um ramo de pesquisa nessa instituição. Esse autor foi, ainda, dos teóricos que mais contribuíram para a discussão de questões referentes à produção e gestão da informação científica, não só na então União Soviética, mas de parte considerável do extinto bloco socialista.

Para que possa ser compreendido qual foi o principal conceito e estrutura que norteou a “vertente soviética” em Ciência da Informação, e, paralelamente, os pensamentos e idéias de Mikhailov, será necessário analisar primeiramente seu principal objeto de estudo, a informação científica. Atualmente, no Brasil e Estados Unidos, esse termo é relacionado á informação produzida por um cientista, pesquisador ou grupo de pesquisa, apresentada em textos e publicações científicas, onde é discutida, disseminada e divulgada em diferentes suportes e canais (PRICE, 1976; MEADOWS, 1999). Na Rússia, numa classificação feita um pouco depois da dissolução da URSS, o termo informação científica foi apresentado como

informação confiável de qualquer campo relacionado às ciências técnicas, naturais ou sociais, obtidos por métodos científicos de estudo e avaliados por cientistas ou grupos de pesquisa (universidades, corpo editorial de um periódico, etc...) (CHERNYI; GILYAREVISKYI; KOROTKEVICH, 1993, p. 3).

Essa análise será necessária por duas razões. A primeira é porque esse conceito foi utilizado anos antes da construção da disciplina Informatika (nomenclatura utilizada na URSS para a Ciência da Informação), chegando a ser proposta por Mikhailov, em colaboração com o pesquisador V. A. Polushkin, em 1963, uma disciplina denominada “Informação Científica” para o estudo da área, o que posteriormente foi rejeitado pelo próprio Mikhailov e por outros autores russos, mas que posteriormente serviria de base para o desenvolvimento do conceito Informatika, em 1966 (MIKHAILOV; CHERNYI; 
GILYAREVSKYI, [1968], 1973). A segunda razão relaciona-se à importância desse objeto de estudo para a produção científica de Mikhailov e colaboradores, recebendo considerável atenção em seus artigos, livros e apresentações em congressos e conferências.

Essa pesquisa pretende analisar a abordagem de Mikhailov, como autor único ou com colaboradores, sobre o conceito informação científica. Serão estudados as definições, características e valores referentes a esse termo apresentados em diferentes trabalhos do autor. Entre essas diferentes publicações, produzidas entre as décadas de 1950 e 1980, as principais fontes de pesquisa serão os livros Fundamentos da Informática (Osvony Informatiki), publicado originalmente em 1968 na URSS, Scientific Communications and Informatics (Nauchnye Kommunikacii i Informatika), publicado na URSS em 1976, e o artigo Estrutura e principais propriedades da informação científica, publicado originalmente em 1975, todos esses trabalhos realizados em conjunto com os autores A. I. Chernyi e R. S. Gilyarevskyi.

Quando possível, também será realizada uma diferenciação da abordagem feita por Mikhailov para esse termo da que era realizada nos Estados Unidos e Europa Ocidental. Paralelamente a essas analises, será feito também um breve histórico da então embrionária área da Ciência da Informação, ente as décadas de 1940 e 1950, onde a nomenclatura informação científica recebeu generoso espaço dentro desse campo de pesquisa, chegando, em alguns momentos, a identificar a área.

\section{E no “inicio” era a informação científica...}

No período entre aproximadamente 1945 e 1961 a Ciência da Informação entrava numa espécie de "segunda” fase de consolidação do seu escopo teórico e prático, onde se “afastava” do conceito Documentação, seja pelas teorias relacionadas ao pesquisador belga Paul Otlet na Europa, seja pelas iniciativas feitas pela ADI (American Documentation Institute) nos Estados unidos que, de certa forma, representaram a emergência da área, entre o final do século XIX até o inicio da década de 1940. Esse afastamento (parcial) se deu com a assimilação de novas idéias e teorias como, por exemplo, a Cibernética, a Recuperação da Informação e a Teoria da Informação, formuladas logo após o final da segunda guerra mundial e com a inclusão da 
nomenclatura informação científica na identificação desse ainda embrionário campo de estudo (PINHEIRO, 2005).

Em relação e essas novas teorias, é citado o artigo de Vannevar Bush "As We May Think”, publicado em 1945 e as obras “Cybernetics: Or the Control and Communication in the Animal and the Machine" (1948), de Norbert Wiener e "A Mathematical Theory of Communication" (1949), de Claude Shannon e Warren Weaver, como importantes contribuições, mesmo que de forma indireta, para o desenvolvimento teórico da Ciência da Informação (PINHEIRO, 2002, p. 73). Muitos dos conceitos utilizados por esses autores seriam aproveitados posteriormente pela área, inclusive na obra de Mikhailov.

Em relação à nomenclatura Informação científica, que em alguns momentos chegou a ser usada para definir o embrionário campo de pesquisa em Ciência da Informação nesse período, as raízes de sua utilização para a área remontam de 1946. Nesse ano, em Londres, foi realizado o Royal Empire Society Scientific Conference, que, entre outros assuntos, discutiu a importância da informação científica e de sua utilização (BARRETO, 2008).

Entre junho e julho de 1948 aconteceu a conferência The Royal Society Scientific Information Conference, também realizada em Londres, parcialmente influenciada pela reunião realizada dois anos antes no país. Com a participação de cerca de 340 profissionais e separados em quatro sessões, essa conferência foi umas das primeiras a discutir não somente aspectos teóricos referentes à informação científica, mas também apresentou variadas abordagens sobre a organização, classificação e reprodução desse tipo de informação, em diferentes suportes e publicações, destinados a institutos de pesquisa, cientistas e outros locais que se utilizavam desse tipo de informação (MCNINCH, 1948; BARRETO, 2008). Apesar de seu escopo não incluir as ciências sociais, a conferência apresentou um forte caráter interdisciplinar e seu resultado foi apresentado em anais, com mais de 700 páginas, que foram publicadas nos Estados Unidos na década seguinte (MCNINCH, 1948; BARRETO, 2008).

Após outras iniciativas realizadas durante grande parte da década de 1950, em novembro de 1958, em Washinghton, foi realizado outro grande congresso que discutiu diferentes aspectos relacionados ao conceito informação científica, com a participação de influentes 
nomes para a Ciência da Informação, como, por exemplo, o físico inglês John Bernal e os pesquisadores Eugene Garfield, Douglas Foskett, Brian Vickery, Mortimer Taube, entre outros. Com cerca de 75 apresentações e publicado na integra, com mais de 1.600 páginas $^{2}$, essa conferência analisou diferentes aspectos relacionados à organização, produção, disseminação, classificação e recuperação da informação científica e seu impacto e utilização, seja para com o cientista ou para a sociedade (BARRETO, 2008). Nessa conferência, foi discutido também diferentes centros e institutos que trabalhavam de alguma forma com a informação científica. A. I. Mikhailov, representando o VINITI, participou desse congresso, apresentando um trabalho mostrando o funcionamento do VINITI e das atividades de informação científica realizadas no instituto. Essa apresentação seria modificada e resumida pelo autor no artigo "Finalidades y problemas de la información científica”, publicado no ano seguinte num periódico relacionado a UNESCO.

A partir de 1961, quando a Ciência da Informação entrou numa "fase conceitual e de desenvolvimento interdisciplinar" (PINHEIRO, 2005), ou seja, de definição de seu campo teórico e de reconhecimento de seu caráter interdisciplinar, o termo rapidamente se afastou do papel de classificar a área, sendo utilizado, muitas vezes, em assuntos relacionados à comunicação científica ou em estudos referentes à bibliometria e a cientometria (para uma analise dessas utilizações, ver, por exemplo, o artigo de Albagli, 1996 e a coletânea organizada por Poblacion, Witter e Silva, 2006).

\section{A. I. Mikhailov e a Informação científica: definição.}

A primeira utilização do termo "informação científica” por A. I. Mikhailov pode ser datada de 1959, quando o periódico Boletín de la Unesco para las Bibliotecas publicou o trabalho "Finalidades y problemas de la información científica". Esse artigo, como apresentado anteriormente, foi uma versão resumida e modificada da apresentação do autor no congresso de informação científica no ano anterior, tratando mais especificamente dos serviços realizados pelo VINITI. Apesar de não haver análise aprofundada do conceito informação científica, é indicado, em algumas partes, a necessidade de um sistema centralizado de organização da informação, o que pode ser exemplificado por sua afirmativa no inicio desse trabalho:

\footnotetext{
${ }^{2}$ Essa conferência está disponível, na integra, no site http://books.nap.edu/openbook.php?record_id=10866\&page=512

(c) Revista Digital de Biblioteconomia e Ciência da Informação,Campinas, v.7, n. 2, p. 27-45, jan./jun. 2010- ISSN: 1678-765X. 
Em nossa época só é possível manter um ritmo acelerado de desenvolvimento cientifico e técnico mediante uma boa organização da informação cientifica. [...] Dado o nível atual de desenvolvimento da ciência [...] é evidente que muitas questões cientificas e técnicas poderiam ser resolvidas com maior rapidez se existisse uma informação ampla e sistemática sobre todos os campos de saber (MIKHAILOV, 1959, p. 267).

Entre 1960 a 1965, Mikhailov trabalhou em diferentes artigos e em dois livros: “A Informação Científica na Engenharia Elétrica”, escrito em conjunto com B. M. Tareev, publicado em 1961, e "Fundamentos da Informação Científica”, de autoria conjunta com Chernyi e Gilyarevskyi, publicado em 1965 e no qual esse conceito é descrito como “informação lógica obtida no processo de conhecimento científico (ou seja, o objeto da atividade de informação científica)” (MIKHAILOV; CHERNYI; GILYAREVSKYI, [1968], 1973, p.53). Entretanto, os autores consideram a Informação científica não somente como um objeto de estudo, relacionado à produção científica, mas também uma espécie de disciplina, o que acabou recebendo consideráveis criticas, com as quais Mikhailov e colaboradores concordaram, buscando então uma nova nomenclatura para a área, fato esse citado na introdução dessa pesquisa (MIKHAILOV, CHERNYI, GILYAREVSKYI, [1968], 1973).

A partir de 1966, até aproximadamente 1971, informação científica foi considerada uma subárea de estudo ou campo cientifico, e depois passou a ser reconhecida como objeto de pesquisa, daí ser delineada a sua estrutura e função.

Mikhailov e colaboradores enfatizaram, primeiramente, que o surgimento desse conceito (e da disciplina Informatika) veio da acumulação, ou do crescimento exponencial da literatura científica e técnica produzida e publicada, causando uma espécie de “crise” ou “explosão” da informação. Em conseqüência, tornou-se necessária uma atividade que permitisse eficiente armazenamento, organização e recuperação desse tipo de informação para apoio ao cientista e pesquisador (MIKHAILOV; CHERNYI; GILYAREVSKYI, [1968], 1973, p. 43; 1969).

Essa preocupação com o crescimento vertiginoso da produção científica seria uma constante na literatura de Mikhailov (como autor único ou com colaboradores) nas décadas seguintes identificando, a partir daí, três características que seriam importantes para o desenvolvimento da informação científica e suas respectivas atividades: 
- Variação do crescimento do número de usuários da informação.

- Crescimento do volume de documentos de caráter científico.

- Desenvolvimento de tecnologias para o processamento e transmissão da informação (MIKHAILOV, 1985, p. 2).

A partir dessa abordagem, a informação científica foi definida como: "Informação lógica obtida durante o processo de conhecimento, o qual reflete adequadamente as leis do mundo objetivo e se utiliza na prática histórico-social” (MIKHAILOV, 1967a, p.239-240).

\section{A. I. Mikhailov e a Informação científica: características.}

Inicialmente, os autores apresentaram quatro características que identificavam o conceito de informação científica: objeto ou tipo de informação obtido durante um processo de leis que regem a "realidade objetiva", isto é, de atividades humanas destinadas, de alguma forma, a transformar a natureza e a sociedade; informação que é processada e generalizada pelo pensamento lógico abstrato, diferenciando a informação científica de dados obtidos aleatoriamente pelo homem, no processo de percepção sensorial; informação que reflete adequadamente as leis da "realidade objetiva", determinando, assim, o desenvolvimento científico obtido e, por ultimo, informação que é aplicada nas práticas históricas e sociais evitando, assim, que outros tipos de informação, como senso comum, ficção científica ou de outros conhecimentos pseudocientíficos sejam classificados como informação científica (MIKHAILOV, 1967, p. 240; MIKHAILOV, CHERNYI, GILYAREVSKYI, [1968], 1973, p. 56-57).

Os autores apresentam também três tarefas fundamentais referentes a esse tipo de informação, sendo as duas primeiras realizadas de forma eficiente:

1. "Re-coleta exaustiva e processamento analítico sintético da informação documental, a fim de prover rapidamente, ao conhecimento dos pesquisadores, os novos avanços técnicos e científicos.

2. Armazenamento prolongado da informação documental, utilizando sistemas que permitam realizar uma busca rápida, exaustiva e multifacetada dos dados solicitados.

3. Processamento da informação por meio de sistema lógico informativo, com o objetivo de obter uma nova informação, por exemplo, a base de "analogias químicas" registradas na memória de uma maquina determinando a possibilidade de síntese dos compostos químicos ainda não obtidos "(MIKHAILOV; CHERNYI; GILYAREVSKYI, [1968], 1973, p. 44).

Outra característica enfatizada pelos autores é a diferença conceitual entre o termo informação científica e a classificação pura de informação, o que foi evitado na 
concepção soviética de Ciência da informação. Essa distinção fica evidenciada na definição dos autores para o objeto informação:

São processos, métodos e leis relativos ao registro, processamento sintético-analítico, armazenamento, recuperação e disseminação da informação científica, mas não a informação científica tal qual atributo de uma respectiva ciência ou disciplina (MIKHAILOV; CHERNYI; GILYAREVSKYI, 1969).

Ainda sobre esse aspecto, Mikhailov apontou as várias denominações que poderiam ser atribuídas ao conceito informação no qual

[...] o termo é usado denotando o controle de sinais em aparelhos automáticos, o código genético dos cromossomos, sinais circulando em células cerebrais e, finalmente, conhecimento disseminado na forma de artigos textuais ou armazenados em banco de dados computadorizados (MIKHAILOV, 1983, p.14).

Essa diferenciação pode ser explicada por três motivos. O primeiro é o interesse de Mikhailov em “especificar” o conteúdo e o tipo de informação estudado pela área, evitando que qualquer outro tipo de informação não relacionada à científica seja incluído nesse tipo de estudo e abordagem. Essa preocupação renderia posteriormente críticas de outros autores, que afirmavam ter a teoria de Mikhailov caráter “restritivo”, apresentando uma área de caráter social, mas com um escopo de estudo mais voltado ao trabalho científico e de pesquisa (ROBERTS, 1976).

O segundo motivo é a vaga interpretação do termo informação (svedeniye em russo) no vocabulário russo. Segundo Gilyarevskyi (2007, p. 41-43), o termo foi introduzido na Rússia a partir da década de 1920, relacionado a noticias e, a partir da década de 1950, utilizado indiretamente em conceitos ligados à Cibernética e, após a década de 1970, passou por definições e concepções divergentes, confusas ou que não se relacionam totalmente com o campo de estudo russo da Ciência da Informação.

O terceiro e último é referente à própria definição informação científica. Pinheiro (1997) afirma que o conceito apresenta diferenças entre a abordagem anglo-saxônica e soviética. Na URSS, diferentemente dos EUA, o termo ciência tem abordagem mais ampla e não se limita à ciência propriamente dita, alcança aspectos culturais, portanto, informação científica se relacionava também a características culturais e sociais, e não somente a aspectos científicos ou tecnológicos, comuns à definição norte-americana ou a de alguns países europeus. 
Seria em 1975, quando foram publicados os trabalhos do congresso promovido pelo FID/RI, que discutiu as características desse tipo de informação, que Mikhailov, Chernyi e Gilyarevskyi identificaram quais estruturas, características e propriedades faziam parte da informação científica ${ }^{3}$.

Baseando-se na obra do pesquisador soviético V. S. Siforov, os autores distinguiram quatro classes e subdivisões hierárquicas, das quais a informação científica é constituída:

1) Informação sobre fatos científicos (classe A);

2) Informação sobre hipóteses científicas, conceitos e teorias que elucidam e combinam a totalidade dos fatos científicos e interação entre eles (classe B);

3) Informação que combina a totalidade dos fatos científicos, hipóteses, conceitos, teorias e leis que formam o fundamento de uma determinada ciência ou campo de conhecimento (classe C);

4) Informação que reflete e forma uma abordagem comum do conhecimento e transformação do mundo que nos cerca (classe D). (SIFOROV apud MIKHAILOV, CHERNYI, GILYAREVSKYI, [1975], 1980, p.73).

Nesse trabalho, segundo os autores, a informação cientifica apresenta 12 propriedades principais:

1. Inseparabilidade da Informação científica de seu suporte físico: Apesar de ter natureza não-material, a informação cientifica não existe sem algum tipo de revestimento material e nem pode ser separada de seu suporte físico. Utilizando o conceito marxista-leninista de reflexo, significa que esse tipo de informação não existe sem um reflexo (como o de um espelho) (MIKHAILOV, CHERNYI, GILYAREVSKYI, [1975], 1980, ps. 75-76).

2. Não-aditividade, não-comutatividade e não-associatividade da informação científica: significa que esse tipo de informação, além de ser a soma total dos elementos de informação científica (por exemplo, palavras), que formam determinada mensagem, esses mesmos elementos não podem ser organizados de forma aleatória e nem grupados em combinações diferentes sem distorcer, de alguma forma, o conteúdo da mensagem (MIKHAILOV; CHERNYI; GILYAREVSKYI, [1975], 1980, p.76).

3. Valor da informação científica: Essa característica está relacionada especificamente ao comportamento do receptor quando recebe uma determinada informação científica. Quanto mais essa informação for incluída na relação entre

\footnotetext{
${ }^{3}$ Esses conceitos também foram reproduzidos, praticamente ipsis litteris, no livro Scientific Communication and
} 
esse receptor e o canal onde essa informação foi transmitida, maior será seu valor. Os autores afirmam também que o conceito de valor é atribuído somente para a informação usada para fins de controle (como, por exemplo, de caráter governamental e administrativo) e que somente tem existência para com os seres vivos, tendo os seres humanos a capacidade de selecionar a informação recebida (MIKHAILOV; CHERNYI; GILYAREVSKYI, [1975], 1980, p.76-77).

4. Natureza social da informação científica: ressalta que a informação científica é uma atividade e um tipo de informação que é percebido pela sociedade humana como um todo (MIKHAILOV; CHERNYI; GILYAREVSKYI, [1975], 1980, p. 77-78).

5. Natureza semântica da informação científica: indica o caráter conceitual da informação científica, na qual os conceitos são os que compõem “o significado de palavras e generalizam as características dos objetos e fenômenos”, pelo ponto de vista do seu conteúdo. Os autores ressaltam, ainda, que "qualquer informação científica é semântica, mas nem toda a informação semântica é científica” (MIKHAILOV; CHERNYI; GILYAREVSKYI, [1975], 1980, p.78-79). A característica "semântica” da informação científica ou até mesmo a tentativa de se medir e classificar ”informação semântica” recebeu considerável atenção de Mikhailov e colaboradores, em diferentes trabalhos. Em uma das primeiras abordagens dessa característica, os autores afirmam que a geração, acumulação e transmissão desse tipo de informação são essenciais para o desenvolvimento científico, técnico e cultural da humanidade, portanto, relacionando diretamente o desenvolvimento de novos meios de divulgação e armazenamento da informação, do meio oral para outros tipos de comunicação, com o progresso humano e da sociedade (MIKHAILOV; CHERNYI; GILYAREVSKYI, [1968], 1973, p. 6667). Posteriormente, os autores buscaram estabelecer um valor para a informação científica, a partir de conceitos de informação semântica de autores como R. Carnap e Bar-Hillel e das tentativas do teórico Yuri Shreider em criar uma teoria semântica da informação (MIKHAILOV; CHERNYI; GILYAREVSKYI, [1976], 1984, p. 83-88).

6. Natureza lingüística da informação científica: significa que a informação científica é lingüística por natureza, pois só consegue ser materializada a partir do resultado de um pensamento universalizado e abstrato, representado por um 
conjunto de símbolos que servem como meio de expressão ou comunicação, ou seja, pela linguagem, podendo ser registrada em diferentes suportes físicos para sua posterior transmissão. (MIKHAILOV; CHERNYI; GILYAREVSKYI, [1975], 1980, p. 79-80).

7. Independência da informação científica da linguagem e do suporte físico: a informação científica não é afetada com a utilização de diferentes suportes físicos para seu armazenamento e nem com a mudança da língua na qual está sendo expressa e onde ocorrem mudanças, mas não a ponto de modificar seu conteúdo (MIKHAILOV; CHERNYI; GILYAREVSKYI, [1975], 1980, p. 80).

8. Não-continuidade da informação científica: traduz que uma informação cientifica pode ser apresentada e disseminada de diferentes maneiras, não seguindo um padrão “contínuo”. Por exemplo, uma determinada informação científica pode ser apresentada tanto em um artigo como em uma palestra ou apresentação em congresso diferenciando, assim, o meio, o suporte e a forma no qual essa informação foi transmitida. (MIKHAILOV; CHERNYI; GILYAREVSKYI; [1975], 1980, p. 81-82).

9. Cumulatividade da informação científica: propriedade relacionada à utilização, organização e avaliação, pelos cientistas e pesquisadores, da informação científica utilizada anteriormente para maior acessibilidade a futuras gerações de pesquisadores. Segundo os autores, essa propriedade é mais nítida nas ciências exatas e naturais (por exemplo, Matemática, Física e Química) (MIKHAILOV; CHERNYI; GILYAREVSKYI, [1975], 1980, p. 82-83).

10. Independência da informação científica de seus criadores: a informação cientifica, depois de gerada se torna independente de quem a criou. Isso significa que uma determinada teoria ou descoberta feita por um cientista ou pesquisador, mesmo não perdendo o papel dado a ele pelo seu "pioneirismo”, é discutida e analisada posteriormente sem enfatizar o caráter "autoral” da descoberta (como é feita numa obra de arte, por exemplo) (MIKHAILOV; CHERNYI; GILYAREVSKYI, [1975], 1980, p. 84-85).

11. Envelhecimento ${ }^{4}$ da informação científica: significa que determinada informação cientifica atinge um envelhecimento completo, ou total obsolescência, quando novas informações científicas mostram que a mesma ou está errada ou é incapaz de ser utilizada adequadamente para refletir os fenômenos do mundo material, da

\footnotetext{
${ }^{4}$ Ou obsolescência (em MIKHAILOV; CHERNYI; GILYAREVSKYI, [1976], 1984, p.80).
} 
sociedade e de determinado pensamento. Em relação ao Envelhecimento “parcial” desse tipo de informação, ou autores apontam certa dificuldade em estipular, com precisão, onde e de que forma a mesma ocorre, dependendo muito da informação produzida e da nova informação que irá acarretar essa obsolescência (MIKHAILOV; CHERNYI; GILYAREVSKYI, [1975], 1980).

12. Dispersão da informação científica: traduz que a informação (seja sob forma de uma hipótese, teoria, noções etc.) agrupada e publicada originalmente por seu criador adquire uma nova "vida" ou função na obra de outros autores, sendo citada, agrupada ou analisada de diferentes maneiras por diferentes autores e cientistas. (MIKHAILOV; CHERNYI; GILYAREVSKYI, [1975], 1980, p. 8687).

Essas propriedades foram identificadas também segundo um esquema hierárquico proposto pelos autores, nos seguintes tipos de informação: informação social e não-social, semântica e nãosemântica e científica e não científica, conforme ilustrados na Figura 1.

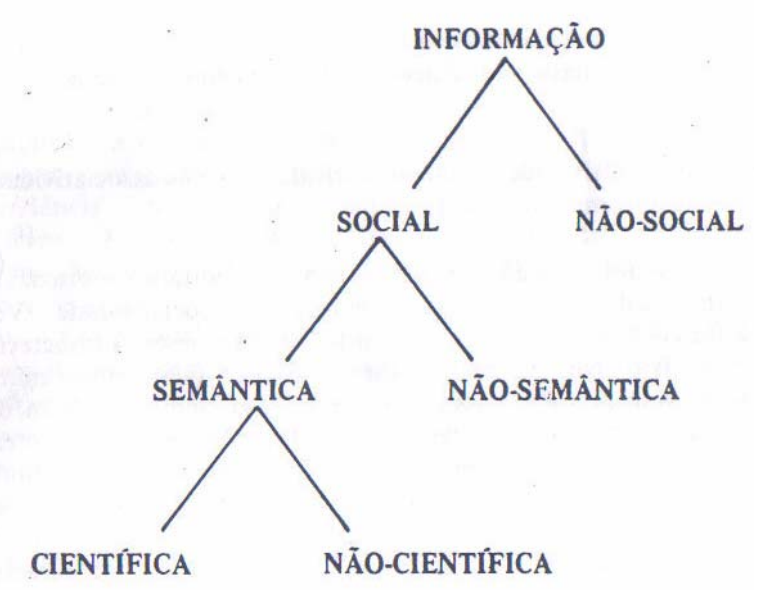

Figura 1: Identificação hierárquica de tipos de informação científica.

Fonte: MIKHAILOV; CHERNYI; GILYAREVSKYI, [1975], 1980, p.75.

A partir desse esquema, os autores identificaram as propriedades de cada tipo de informação, devidamente assinaladas na Figura 2. 


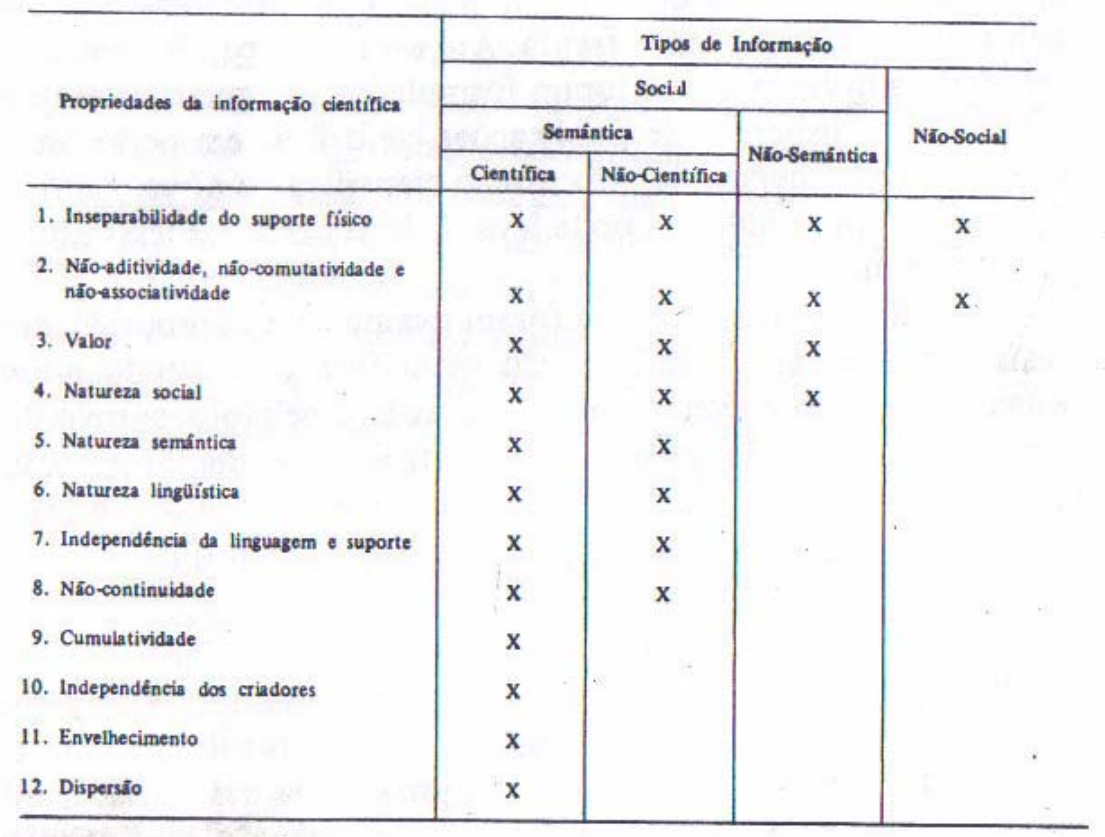

Figura 2: Indentificação das propriedades e tipos de informação científica. Fonte: MIKHAILOV, CHERNYI, GILYAREVSKYI, [1975], 1980. p. 88.

Além dessas propriedades, os autores enfatizaram dois outros valores ou funções relacionados à informação científica.

O primeiro valor seria o "econômico”, que poderia ser atribuído a esse tipo de informação e à atividade de informação científica. Sobre essa questão, Mikahilov, em trabalho de 1972 destaca que num primeiro momento, há facilidade em se calcular economicamente os custos e os ganhos financeiros advindos de atividades de informação científica, porém, não seus benefícios e vantagens para um determinado organismo ou empresa que investe ou que se utiliza desse serviço. Mikhailov (1972) afirma que esse tipo de atividade deve ser discutido de forma muito mais ampla do que simplesmente do custo ou do lucro advindo devendo ser analisado também fatores como, por exemplo, o rápido suporte dado ao especialista para uma idéia ou pesquisa que precisa rapidamente dessa informação permitindo, assim, um suporte realmente qualitativo para o campo cientifico e técnico

Ao analisar de forma mais aprofundada essa questão, Mikhailov; e colaboradores procuraram diferenciar a informação científica de um bem econômico qualquer, reconhecendo que alguns tipos de informação científica não podem ter seu valor econômico, devido a sua utilização para a sociedade e a ciência, e que sua estrutura não permite sua "possessão", isto é, não pode ser patenteada, comprada ou vendida, mesmo que as atividades, a forma em que a mesma é publicada ou disponibilizada (livros, 
periódicos, artigos, etc...) possam ter seu valor econômico medido ${ }^{5}$ (MIKHAILOV, CHERNYI, GILYAREVSKYI, [1976], 1984, ps. 88-93).

A segunda, em relação ao caráter social da informação científica e de sua disseminação, Mikhailov, em trabalho publicado em 1984, assinala que o acesso à informação para a sociedade deve ser colocado como a principal norma ética da área. Esse autor afirma, ainda, que a partir de eficientes serviços de informação cientifica, os cidadãos e principalmente cientistas e pesquisadores, devem ter rápido acesso à informação da qual necessitam em determinada pesquisa ou estudo (MIKHAILOV, 1984, p. 2).

Ainda em relação a essa característica social da informação científica e da Ciência da Informação, devem ser citados os trabalhos da professora Isa Freire, que em diferentes ocasiões (FREIRE, 2003, 2004) apresentou e evidenciou essa propriedade nas idéias de Mikhailov e colaboradores. Segundo a autora, os pensamentos dos autores representavam a expectativa de uma atuação social mais ampla da Ciência da Informação, onde os pesquisadores da área podiam "vislumbrar os problemas da informação em nova perspectiva, orientando seu interesse teórico para além dos limites das atividades do campo científico” e esses profissionais poderiam ser apresentados como “[...] mediadores no processo de comunicação social, em especial nas situações de comunicação do conhecimento de natureza técnica e científica para os diversos grupos da sociedade” (FREIRE, 2003, p. 57).

Por outro lado, a autora, de certa forma repetindo as já citadas críticas de Roberts (1976), afirma que "apesar da visão social, Mikhailov e colaboradores restringiam a prática da ciência da informação ao campo das atividades científicas e técnicas, excluindo da sua perspectiva a explicitação de outros grupos sociais” (FREIRE, 2004).

Em outro trabalho, Mikhailov; Chernyi e Gilyarevskyi, [1976], 1984, analisam a percepção e a recepção da informação científica produzida e divulgada, pela sociedade e cientistas. Segundo os autores, para a sociedade, a descoberta de uma nova teoria científica, se não chega a ser desprezada, também não recebe a atenção ou a importância que a mesma deveria obter. Isso acontece, segundo os autores, possivelmente pelo

\footnotetext{
${ }^{5}$ Nessa parte, a análise de Mikhailov e colaboradores baseia-se em concepções do marxismo-leninismo e a realidade soviética da época, onde existia oposição a uma concepção de lucro acerca da atividade científica.
} 
desconhecimento das pessoas em relação a essa teoria ou também por não conseguirem assimilar de imediato as complexas fórmulas ou idéias que essas teorias muitas vezes apresentam.

Os autores destacam, ainda, que as descobertas e informações científicas muitas vezes se encontram em forma “prematura”, e nesse estágio a mesma não recebe apoio e atenção, nem da sociedade nem da classe cientifica, que às vezes, por diferentes motivos, pode recebê-las, até mesmo com certa hostilidade. Isso não significa que a teoria ou o conceito proposto esteja errado, pelo contrário. Porém, segundo os autores, na realidade na qual as idéias foram propostas, muitas vezes as mesmas não chegam a ser assimiladas de forma correta (MIKHAILOV; CHERNYI; GILYAREVSKYI, [1976], 1984).

Mikhailov, Chernyi, Gilyarevskyi ([1976], 1984) citaram diferentes exemplos para corroborar essa opinião, como algumas importantes descobertas que somente tiveram seu reconhecimento e real utilização décadas depois de serem apresentadas por seus autores.

Ao discutir o aspecto econômico e da receptividade da sociedade para com a informação cientifica, os autores buscam (indiretamente) justificar sua abordagem sobre o caráter “social” da informação cientifica em sua teoria. O foco de sua atenção é a sua assimilação e acessibilidade pelos pesquisadores e cientistas, que podem codificar e apresentar essas informações para a sociedade.

A partir da abordagem do caráter social da informação científica, serão analisadas obras ou correntes de pensamento que influenciaram ou nortearam a teoria de Mikhailov sobre esse tipo de informação.

\section{A. I. Mikhailov e a Informação científica: Influências.}

Em um primeiro momento, estudando os trabalhos elaborados pelo autor entre 1958 até 1986, foi percebido que Mikhailov estudou conceitos e idéias de pesquisadores norteamericanos, europeus ou de outros países ocidentais relacionando, assim, a teoria desenvolvida pela Ciência da Informação na União Soviética com a que era, paralelamente, formulada no ocidente. Mikhailov aborda, por exemplo, refutando ou

(c) Revista Digital de Biblioteconomia e Ciência da Informação,Campinas, v.7, n. 2, p. 27-45, jan./jun. 2010- ISSN: 1678-765X. 
corroborando, vários conceitos apresentados por autores como Derek Solla Price ou Brian Vickery, constantemente citados e analisados em sua obra, além de outros autores ocidentais. Esse procedimento, natural entre cientistas, embora mais difícil naquela fase, entre soviéticos e anglo-saxões, também é percebido nas obras e trabalhos de outros autores soviéticos em periódicos ou em artigos publicados pela FID. Essa constatação reflete que no campo da Ciência da informação na URSS foram estudados trabalhos e obras de outros países fora do bloco comunista e, também, em algumas ocasiões, chegou a haver interação com pesquisadores desses outros campos de pesquisa e países.

Mikhailov e seus colaboradores enfocaram, de forma extensiva, em alguns casos, conceitos e teorias desenvolvidos por autores como Karl Marx, Friedrich Engels e Lênin, entre outros da corrente de pensamento Marxista-leninista, a principal no país até o inicio dos anos $1990^{6}$. Mesmo que em certos trabalhos, as idéias desses teóricos não chegassem a serem relacionadas, de forma satisfatória, aos conceitos desenvolvidos por Mikhailov, essas fontes são utilizadas em várias ocasiões e em diferentes textos do autor, tentando relacionar a Informatika a uma visão “social” da área ou apenas tentando adaptar a Ciência da Informação à realidade em que Rússia vivia naquele período.

Outra importante influência que apareceu na obra de Mikhailov e de outros autores soviéticos, nas décadas de 1950 a 1970, foi a do físico inglês John Bernal. Em seu livro “O estudo social da ciência”, publicado originalmente em 1939, apareceu um dos primeiros conceitos de "sociologia da ciência", vertente que “[...] trata de examinar o fenômeno científico como um fato social” (SCHWARTZMAN, 1984), que foi consideravelmente estudada ou citada por Mikhailov e colaboradores em alguns de seus trabalhos.

\section{Considerações finais}

Essa pesquisa buscou estudar o conceito informação científica a partir das idéias do pesquisador soviético A. I. Mikhailov em sua produção bibliográfica, como autor único

\footnotetext{
${ }^{6}$ Em relação a Lênin, Brookes (1984, p.221) afirma que o líder soviético, por diferentes razões, manteve-se atento às teorias da Documentação, relacionadas aos teóricos Paul Otlet e Henry La Fountaine, bem como a conceitos desenvolvidos pelo Instituto Internacional de Bibliografia- IIB, na Bélgica e na Sociedade Real inglesa, o que permitiu a ele criar e desenvolver um sistema de informação cientifica na Rússia, nos primeiros anos após 1917. Esse fato explica parcialmente o motivo pelo qual Lênin possuía textos que discutem conceitos relacionados à documentação, bibliotecas
} 
ou com colaboradores. A análise de Mikhailov para esse termo foi iniciada no final da década de 1950 e recebeu diferentes classificações e abordagens, obtendo uma maior consistência (e estabilidade) teórica a partir de 1967 e, mais especificamente, entre 1974 e 1975, quando são definidos e apresentados suas características e valores.

Foi percebido que, apesar da abordagem feita por Mikhailov e colaboradores se diferir da que era realizada nos Estados Unidos e em boa parte da Europa, o autor buscou um objeto de estudo para área mais “elaborado” e com algumas delimitações epistemológicas, e não tão amplo como o conceito puro de informação. Como visto no decorrer da pesquisa, embora existindo diferentes termos e interpretações de Ciência e Informação na Rússia, parte considerável do que foi apresentado pelos autores, em inúmeros trabalhos, pode e foi utilizado por pesquisadores norte-americanos e brasileiros, principalmente no que diz respeito aos atributos da informação científica.

Também devem ser citados os valores considerados para esse tipo de informação e a atividades com esta relacionada como, por exemplo, o valor “econômico” e o valor “social”, seja referente à necessidade de se trabalhar essa informação para a sociedade, seja ao analisar como a sociedade recebe ou assimila esse tipo de informação.

Mesmo que as críticas de Roberts (1976) e Freire (2004) sobre a ambigüidade e o caráter restritivo desse aspecto "social” nos trabalhos de Mikhailov e colaboradores possam ser corretas, em certos ângulos, não pode ser ignorado que os autores assumiram postura e abordagem até mesmo inovadora, principalmente se considerarmos que nos Estados Unidos, Brasil e Europa Ocidental, no mesmo período (final da década de 1960 e inicio da de 1970), a área estava ainda embrionária na sua construção científica e abordagens.

Esta pesquisa pode ser concluída com a afirmativa de que o pensamento e idéias de Miklhailov, ao lado de outros pesquisadores norte-americanos, soviéticos e da Europa ocidental contribuíram, direta ou indiretamente, para sedimentar sólida base teórica e conceitual para a nomenclatura informação científica. Estes fundamentos permitiram a sua sustentação e, a partir da década de 1950, da utilização dessa nomenclatura para o campo de estudo relacionado à Ciência da Informação.

e de análise, ainda primitiva, acerca do conceito informação cientifica (MIKHAILOV, CHERNYI, GILYAREVSKYI [1976] 1984, p.247-260).

(c) Revista Digital de Biblioteconomia e Ciência da Informação,Campinas, v.7, n. 2, p. 27-45, jan./jun. 2010- ISSN: 1678-765X. 


\section{Referências bibliográficas}

ALBAGLI, S. Divulgação científica: informação científica para a cidadania? Ciência da Informação, v. 25, n. 3, p. 396-404, 1996.

BARRETO, A. A. Uma quase história da ciência da informação. DatagramazeroRevista de Ciência da Informação, v. 9, n. 2, 2008.

BROOKES, B. C. Lenin: the founder of informatics. Journal of Information Science, v. 8, p. 221-223, 1984.

CHERNYI, A. I.; GILYAREVISKYI, R. S.; KOROTKEVICH, L. S. National system of scientific and technical information of the Russian Federation: a draft development program. Scientific and Technical Information Processing, v. 20, n. 2, p. 1-38, 1993.

FREIRE, I. M. O olhar da consciência possível sobre o campo científico. Ciência da Informação, Brasília, v. 32, n. 1, p. 50-59, 2003.

FREIRE, I. M. A responsabilidade social da Ciência da Informação na perspectiva da consciência possível. In: Datagramazero-Revista de Ciência da Informação, v. 5, n.1, 2004.

GILYAREVISKYI, R. S. Information Culture in Higher Education. Scientific and Technical Information Processing, v. 34, n. 1, p. 40-43, 2007.

MCNINCH, J. H. The Royal Society Scientific Information Conference. Londres, 1948. Disponível em: < http://dgz.org.br/abr08/F_I_art.htm>

MEADOWS, A. J. A comunicação científica. Brasília: Briquet de Lemos, 2000.

MIKHAILOV, A. I. Finalidades y problemas de la información científica. Boletin de la UNESCO para las Bibliotecas, Havana, v. 13, p. 267-270, 1959.

MIKHAILOV, A. I. Informatics: a scientific discipline. Documentação e Informação Científica, Lisboa, v. 10, n. 53, p. 239-242,1967.

. L'informazione scientifica e tecnica e l'efficacia della scienzia. Rivista della

Informazione, v.3, n.1, p.7-10, 1972. 17, 1983.

Information science and an informed society. ASIS Bulletin, v. 10, n. 1, p. 14-

. Information in a Developing World. In: International Forum on Information and Documentation, v.9, n. 3, p. 1-2, 1984.

. The future of scientific information. In: Scientific and Technical Information Processing, New York, v. 12, n.1, p.1-5, 1985.

.; CHERNYI, A. I.; GILYAREVSKY, R.S. Informatics: its scope and methods. In: <ILHAILOV, A. On theoretical problems of informatics. Mouciu: FID/Comitê de Estudo sobre Pesquisa de Base Teórica da iInformação. Moscou: Viniti, 1969.

(c) Revista Digital de Biblioteconomia e Ciência da Informação,Campinas, v.7, n. 2, p. 27-45, jan./jun. 2010-ISSN: 1678-765X. 
Fundamentos de la informatica. Habana: IDICT/Academia de Ciências de Cuba. Havana IDICT, 1973. 2 v.

. Estrutura e principais propriedades da informação científica. In: GOMES, Hagar. Espanha. (Org.). Ciência da informação ou informática? Rio de Janeiro: Calunga, 1980.

1984.

Scientific communications and informatics, Arlington: Information Resources,

PINHEIRO, L. V. R. A ciência da informação entre luz e sombra: domínio epistemológico e campo interdisciplinar. 1997. Tese (Doutorado em Comunicação) Universidade Federal do Rio de Janeiro, 1997.

PINHEIRO, L. V. R. Gênese da Ciência da Informação ou sinais anunciadores da nova área. In: O campo da Ciência da Informação: gênese, conexões e especificidades. João Pessoa, UFPB, p. 61-86, 2002.

Processo evolutivo e tendências contemporâneas da Ciência da Informação.

Informação e Sociedade, João Pessoa, v. 15, n. 1, 2005.

POBLACION, D. A.; WITTER, G. P.; DA SILVA, J. F. M. (Org.). Comunicação e produção científica: contexto, indicadores, avaliação. São Paulo: Angellara, 2006.

PRICE, D. J. S. O desenvolvimento da ciência. Rio de Janeiro: Livros Técnicos e Científicos, 1976.

ROBERTS, N. Social considerations towards a definition of information Science.

Journal of Documentation, v. 32, n. 4, p. 249-57, 1976.

SCHWARTZMAN, S. Ciência da ciência. Ciência Hoje, Rio de Janeiro, v. 2, n. 11, p. 54-59, 1984. Disponível em: http://www.schwartzman.org.br/simon/ciencia2.htm.

Roberto Lopes dos Santos Junior

Mestre em Ciência da Informação pelo convênio PPGCI/ IBICT/ UFF.

bobblopes@hotmail.com

\section{Lena Vania Ribeiro Pinheiro}

Doutora em Comunicação e Cultura pelo convênio PPGCI / IBICT/ UFRJ-ECO.

lenavania@ibict.br

Recebido em: 07/05/2009

Aceito para publicação em: jul/2009

(c) Revista Digital de Biblioteconomia e Ciência da Informação,Campinas, v.7, n. 2, p. 27-45, jan./jun. 2010- ISSN: 1678-765X. 